\title{
BMJ
}

\section{Long term prognosis in preschool children with wheeze: longitudinal postal questionnaire study 1993-2004}

\author{
Peter I Frank, director, ${ }^{1}$ Julie A Morris, head of medical statistics, ${ }^{2}$ Michelle L Hazell, senior research \\ associate, ${ }^{1}$ Mary F Linehan, senior research associate, ${ }^{1}$ Timothy L Frank, director ${ }^{1}$
}

${ }^{1}$ General Practice Research Unit, North West Lung Research

Centre, Wythenshawe Hospital, Manchester M23 9LT

${ }^{2}$ Department of Medical Statistics, University Hospital of South Manchester NHS Foundation Trust, Manchester

Correspondence to: $\mathrm{M} \mathrm{L}$ Hazell michelle.hazell@manchester.ac.uk

doi:10.1136/bmj.39568.623750.BE

\section{ABSTRACT}

Objectives To follow a population of preschool children with and without parent reported wheeze over a period of 6-11 years to determine prognosis and its important predictive factors.

Design Longitudinal series of five postal surveys based on the international study of asthma and allergies in childhood questionnaire carried out between 1993 and 2004.

Setting Two general practice populations, south Manchester.

Participants 628 children aged less than 5 years at recruitment and those with at least six years' follow-up data.

Main outcome measures Parent completed questionnaire data for respiratory symptoms and associated features. Results Of 628 children included in the study, 201 (32\%) had parent reported wheeze at the first observation (baseline), of whom $27 \%$ also reported the symptom on the second occasion (persistent asthma). The only important baseline predictors of persistent asthma were exercise induced wheeze (odds ratio 3.94, 95\% confidence interval 1.72 to 9.00 ) and a history of atopic disorders $(4.44,1.94$ to 10.13$)$. The presence of both predictors indicated a likelihood of $53.2 \%$ of developing asthma; if only one feature was present this decreased to $17.2 \%$, whereas if neither was present the likelihood was $10.9 \%$. Family history of asthma was not predictive of persistent asthma among children with preschool wheeze.

Conclusion Using two simple predictive factors (baseline parent reported exercise induced wheeze and a history of atopic disorders), it is possible to estimate the likelihood of future asthma in children presenting with preschool wheeze. The absence of baseline exercise induced wheeze and a history of atopic disorders reduces the likelihood of subsequent asthma by a factor of five.

\section{INTRODUCTION}

Wheeze is common in preschool children; several major studies have reported a prevalence of between $25 \%$ and $38 \%$. $^{1-5}$ In most of these cases, however, it is thought that the symptom is transient and resolves by the age of 5 years, being associated with low premorbid lung function, compatible with narrowed airways and often presenting only during viral infections. ${ }^{6}$ The precise diagnosis of wheeze in these children is often problematic, ${ }^{7}$ whereas the reporting of wheeze in older children has been used to represent a diagnosis of asthma in some epidemiological studies. ${ }^{589}$

Although most cases of asthma begin in early childhood, it has been difficult to predict which preschool children with wheeze develop asthma in later years. ${ }^{1}$ One of the most crucial problems has been the lack of solid data on the natural history of the disease. ${ }^{2}$ Although cross sectional studies can measure prevalence at various points in time and place, a longitudinal approach is needed to study both the natural course of the disease and the outcome of respiratory symptoms.

Determining the long term outcome for preschool children with wheeze and the effect of potential predictors should improve the long term management of affected children and also assist in healthcare planning.

Several longitudinal studies of respiratory symptoms in preschool children have variously found reduced lung function, sensitisation to allergens, and a family history of asthma as important predictors of persistent wheezing. ${ }^{131011}$ The predictive value of other features of preschool wheeze has, however, been little reported.

The present longitudinal study forms part of the Wythenshawe community asthma project, ${ }^{12}$ a long term study examining the natural course of respiratory symptoms and asthma in two general practice populations. We followed the progress of children aged less than 5 years with and without parent reported wheeze at recruitment (baseline) over a period of 6-11 years. We determined the prevalence of persistent and transient wheeze and examined the effect of potential predictors on these outcomes to develop a system for use in primary care to predict the likelihood of children with preschool wheeze having asthma in later years.

\section{METHODS}

A detailed account of the methods used by the Wythenshawe community asthma project has been described previously. ${ }^{13}$ In summary, five postal surveys were carried out in two general practice populations in 1993, 1995, 1999, 2001, and 2004. The 
Table 1/Year of completion of questionnaires by parents and percentage prevalence of wheeze in children in most recent survey

\begin{tabular}{lccc} 
No of children & $\begin{array}{c}\text { Years of } \\
\text { questionnaire reply }\end{array}$ & Wheeze & P value \\
191 & 1993,2004 & 14.1 & \\
\hline 190 & 1993,2001 & 17.4 & \multirow{2}{*}{0.84} \\
\hline 138 & 1995,2004 & 16.7 & \\
\hline 109 & 1995,2001 & 16.5 & \\
\hline
\end{tabular}

practices are situated on a housing estate in south Manchester with evidence of socioeconomic deprivation. ${ }^{14}$ For each survey we sent questionnaires to the parents or guardians of all children (age less than 16 years) on the practice registers. Reminders were sent to non-responders after four and eight weeks. Persistent non-responders either no longer lived at the mailing address or simply did not reply. For the 1993 survey the proportion of people no longer living at the mailing address was estimated to be $5.4 \%$ of mailed adults. ${ }^{12}$ This was calculated by identifying, from a 5\% random sample of non-responders, those people who were not on the electoral register at the mailing address or in the telephone directory and who had not consulted at the practice in the past year. The same proportion was assumed for children and was used for subsequent surveys. The parent completed questionnaire used on each occasion was based on that used by the international study of asthma and allergies in children. ${ }^{15}$ As no agreed definition of asthma in preschool children exists, we used the symptom of wheeze as a marker for respiratory disease. The principal inquiry used for these analyses was whether the children had had wheezing or whistling in the chest in the past 12 months.

We considered four mutually exclusive cohorts for inclusion in the analyses according to the receipt of two parent completed questionnaires (table 1). As a comparison of the prevalence of wheeze in the second survey showed no significant differences between the four cohorts we combined these for the present analyses.

We included only children aged less than 5 years at baseline and excluded those with no available followup information or with follow-up shorter than six years. We categorised children according to the presence or absence of wheeze in the past year at the first observation (baseline), and in those for whom wheeze

Table 2 | Percentages and differences ( $95 \%$ confidence intervals) between children with available data for both surveys and those with baseline data only

\begin{tabular}{lccc} 
Baseline characteristic & Two surveys $(\mathrm{n=628)}$ & Baseline only $(\mathrm{n}=\mathbf{5 0 3})$ & Difference $(\mathbf{9 5 \%} \mathrm{Cl})$ \\
\hline Age $\ll 3$ years & 58.9 & 54.5 & $4.4(-1.37$ to 10.3$)$ \\
\hline Girl & 47.8 & 46.7 & $1.1(-4.9$ to 6.9$)$ \\
\hline Wheeze present & 32.0 & 37.0 & $5.0(-10.5$ to 6.1) \\
\hline Family history of asthma & 63.4 & 60.6 & $2.7(-3.0$ to 8.4) \\
\hline History of atopic disorders* & 28.2 & 26.6 & $1.5(-3.7$ to 6.8) \\
\hline *Hay fever or eczema. & & & \\
\hline
\end{tabular}

was reported, according to the presence of any of four associated features-parental reports of the children being woken by wheeze at least once a week, speech being disturbed by wheeze, exercise induced wheeze, and more than three attacks of wheeze in the past year. These features were defined by questions in the questionnaire used in the international study of asthma and allergies in childhood.

According to parental responses to the first and last surveys we categorised the children into four outcome categories: no wheeze (wheeze not reported in either survey), late onset asthma (wheeze reported in last survey but not in first), persistent asthma (wheeze reported in both surveys), and transient wheeze (wheeze reported in first survey but not in last).

We used wheeze reported in the second survey as a marker for asthma, as in several other epidemiological studies. $^{589}$

\section{Analysis}

Outcomes were examined in two ways. We calculated the crude prevalence by dividing the number of children in an outcome category by the total number of children included in the particular analysis. Prognosis was examined by determining the proportion of children with wheeze at baseline who developed persistent asthma and the proportion in whom the symptom was classified as transient. For those for whom no wheeze was reported at baseline, we calculated the proportion with late onset asthma.

To determine the likelihood of having parent reported wheeze in school years, we categorised children according to whether or not wheeze was reported at recruitment. We estimated the effect of potential predictors on prognosis using multiple logistic regression analysis and multinomial logit models, treating each child as the unit of analysis. This effect was expressed as a regression coefficient with 95\% confidence interval and $\mathrm{P}$ value.

For children with parent reported wheeze at recruitment, potential predictors included were the four associated features of wheeze, age at entry into the study, sex, a family history of asthma, and a history of hay fever or eczema. As this was a large population questionnaire survey, it was not feasible to do formal testing for atopy, therefore we used a history of hay fever or eczema as a marker for atopic disorders. For children with no wheeze reported at recruitment we included the potential predictors of age at entry into the study, sex, a family history of asthma, and a history of atopic disorders. As the association between cohort and prevalence of wheeze was weak, we included cohort as a potential predictor in both analyses.

To estimate the likelihood of asthma after age 5 years we also used multivariate analysis, but included only those potential predictors that had reached a $5 \%$ significance level in the first analysis.

\section{RESULTS}

Response rates for all children decreased progressively over the 11 years of the study. After adjustment for non- 
Table 3 Effect of potential predictors on prevalence of persistent wheeze among children with baseline wheeze adjusted for other potential predictors and cohort effect $(n=201)$

\begin{tabular}{lcc} 
Variable & Adjusted odds ratio $(95 \% \mathrm{Cl})$ & P value \\
>3 attacks of wheeze in past year & $1.53(0.70$ to 3.35$)$ & 0.29 \\
\hline Woken by wheeze & $1.71(0.80$ to 3.66$)$ & 0.17 \\
\hline Speech affected by wheeze & $0.82(0.32$ to 2.08$)$ & 0.67 \\
\hline Exercise induced wheeze & $3.94(1.72$ to 9.00$)$ & 0.001 \\
\hline Age (one year) & $1.29(0.91$ to 1.82$)$ & 0.15 \\
\hline Boy & $1.99(0.95$ to 4.16$)$ & 0.07 \\
\hline History of atopic disorders* & $4.44(1.94$ to 10.13$)$ & 0.001 \\
\hline Family history of asthma & $0.58(0.17$ to 2.04$)$ & 0.40 \\
\hline Cohort (reference $1995-2001):$ & & 0.14 \\
\hline $1993-2001$ & $0.31(0.06$ to 1.48$)$ & 0.19 \\
\hline $1995-2004$ & $0.28(0.04$ to 1.84$)$ & 0.05 \\
\hline $1993-2004$ & $0.07(0.005$ to 1.02$)$ & 0.23 \\
\hline Overall cohort effect & - & \\
\hline
\end{tabular}

*Hay fever or eczema.

responders who no longer lived at the mailing address, response rates were $77 \%$ for the 1993 survey, $74 \%$ for the 1995 survey, $69 \%$ for the 2001 survey, and $47 \%$ for the 2004 survey. As no data were available for the age of non-responders for the first three surveys it was not possible to do separate analyses of response rates for children aged less than 5 years.

A total of 1281 children aged less than 5 years had baseline data available for 1993 or 1995 . Of these, 628 (49.0\%) had 6-11 years of follow-up and were included in the analyses. Children for whom only baseline information was available and therefore were excluded from the study were similar to those included in the analyses for age, sex, wheeze, family history of asthma, and history of atopic disorders (table 2).

Overall, 147 of the $628(23.4 \%)$ children had transient wheeze; wheeze was persistent in $54(8.6 \%)$ and they were classified as having persistent asthma, and $47(7.5 \%)$ were categorised as having late onset asthma. The remaining $380(60.5 \%)$ reported no wheeze in either survey. Thus, of 201 children with reported wheeze at baseline, $26.8 \%$ were classified as having persistent asthma.

Only two potential predictors had a significant effect on the prevalence of persistent asthma: history of atopic disorders (odds ratio 4.44, 95\% confidence interval 1.94 to $10.13, \mathrm{P}<0.001)$ and exercise induced wheeze $(3.94,1.72$ to $9.00, \mathrm{P}=0.001$; table 3$)$. Of 201 children with wheeze at baseline $37.8 \%$ and $52.7 \%$ had these potential predictors, respectively.

Table $4 \mid$ Likelihood of wheeze at second observation among children with wheeze at baseline $(n=201)$

\begin{tabular}{|c|c|c|c|}
\hline Baseline predictors & $\begin{array}{l}\text { No (\%) without wheeze at } \\
\text { second observation }\end{array}$ & $\begin{array}{l}\text { No (\%) with wheeze at } \\
\text { second observation }\end{array}$ & Total \\
\hline None & $41(89.1)$ & 5 (10.9) & 46 \\
\hline $\begin{array}{l}\text { Exercise induced wheeze or history of } \\
\text { atopic disorders* }\end{array}$ & 77 (82.8) & $16(17.2)$ & 93 \\
\hline $\begin{array}{l}\text { Exercise induced wheeze and history of } \\
\text { atopic disorders* }\end{array}$ & $29(46.8)$ & $33(53.2)$ & 62 \\
\hline
\end{tabular}

*Hay fever or eczema.
To predict the likelihood of asthma in school years in those presenting with wheeze at age less than 5 years, only the two significant predictors were included in the analysis (table 4). Less than 11\% of children with preschool wheeze but no added predictors reported the symptom in the second survey, compared with $17.2 \%$ of those who presented with exercise induced wheeze or a history of atopic disorders, and $53.2 \%$ of those with both predictors.

The effects of potential predictors on the reporting of wheeze at the second observation in those who did not have wheeze at the first observation was examined. A history of atopic disorders was the only significant predictor of late onset asthma $(2.78,1.45$ to 5.34 , $\mathrm{P}=0.002)$. Being male $(1.93,1.00$ to $3.71, \mathrm{P}=0.05)$ and having a family history of asthma $(2.28,0.92$ to 5.63 , $\mathrm{P}=0.75$ ) did not reach statistical significance (table 5).

\section{DISCUSSION}

Among preschool children with wheeze, we identified exercise induced wheeze and a history of atopic disorders as predictors of the development of persistent respiratory symptoms in later childhood. This population study followed the natural course of wheeze in more than 600 children aged less than 5 years at entry, over a period of 6-11 years. In the absence of an accepted definition of asthma in preschool children, we used wheeze as a marker of respiratory disease. For school aged children, we followed other epidemiological studies and used wheeze in the past year as a marker of asthma. ${ }^{589}$

About one third of preschool children were reported to have had wheeze in the past year, almost three quarters of whom were categorised to have only transient symptoms. These results, although not directly comparable, are similar to those reported in three other large studies. ${ }^{12}{ }^{16}$ Categorisation of wheezing into never, transient, persistent, and late onset was similar to that used in another British study. ${ }^{17}$

The only significant predictors of persistent asthma were a report of exercise induced wheeze at baseline and a history of hay fever or eczema. No significant difference was found between the size of effect exerted by each. None of the other associated features of wheeze at baseline had any significant effect on prognosis. As wheeze in preschool children is recognised to be a common presenting symptom, in most cases transient, it would be of great importance to identify young children with wheeze who develop asthma in later life. Parents of children with little risk could be reassured, and healthcare planning programmes could be developed for the minority at greater risk of developing asthma. In the present study only half $(53.2 \%)$ of the children presenting with preschool wheeze together with both exercise induced wheeze and a history of atopic disorders developed persistent asthma, whereas if only one of these predictors was present the likelihood fell to $17.2 \%$. If neither was present, the likelihood of later asthma was only $10.9 \%$. 
Table 5 Effect of potential predictors on prevalence of late onset wheeze among children without wheeze at baseline adjusted for other potential predictors and cohort effect $(n=427)$

\begin{tabular}{lcc} 
Variable & Adjusted odds ratio $(95 \% \mathrm{Cl})$ & P value \\
Age (one year) & $1.07(0.80$ to 1.42$)$ & 0.66 \\
\hline Boy & $1.93(1.00$ to 3.71) & 0.05 \\
\hline History of atopy* & $2.78(1.45$ to 5.34$)$ & 0.002 \\
\hline Family history of asthma & $2.28(0.92$ to 5.63$)$ & 0.75 \\
\hline Cohort (reference 1995-2001): & $1.10(0.28$ to 4.28) \\
\hline 1993-2001 & $0.79(0.16$ to 3.91) & 0.89 \\
\hline $1995-2004$ & $0.56(0.06$ to 5.47) & 0.77 \\
\hline $1993-2004$ & - & 0.58 \\
\hline Overall cohort effect & & 0.72 \\
\hline
\end{tabular}

*Hay fever or eczema.

This study supports the findings of several longitudinal surveys that reported atopy as a prognostic factor in the development of persistent symptoms ${ }^{13611}$ but goes on to examine the prognostic effect of other features, including number of attacks, wheeze affecting speech, or being affected by exercise. A history of atopic disorders was the only significant predictor of late onset asthma.

It is possible that boys may be at greater risk of wheeze persisting into later childhood, as this factor was on the borderline of statistical significance. This may be of particular interest in the context of changes in the male to female ratio for respiratory symptoms and asthma. Surveys carried out among older Scottish schoolchildren showed that the male to female ratio of parent reported wheeze in the previous three years narrowed between 1989 and $2004 .^{18}$

We considered several potential sources of bias. Assessment of symptoms in epidemiological studies is subject to measurement error leading to biased estimates of prevalence and remission in longitudinal studies. ${ }^{19}$ Although this cannot be ruled out here, the use of identical questionnaires on four occasions reduced the likelihood of such bias. Selection bias was also reduced in that this was a general population survey rather than one that included specific groups, such as those at risk of asthma. ${ }^{20}$ In addition, two reminders were sent to non-responders in each survey to maximise response rate.

The four surveys had adjusted response rates between $47 \%$ and $77 \%$. The estimate of $5.4 \%$ of nonresponders who no longer lived at the mailing address,

WHAT IS ALREADY KNOWN ON THIS TOPIC
It has been difficult to predict which preschool children with wheeze will go on to develop
asthma
Identifying simple predictive factors would improve the long term management of children
and help in the planning of healthcare provision
WHAT THIS STUDY ADDS
Exercise induced wheeze and a history of atopic disorders in preschool children are
significant predictors of future asthma
The absence of these two factors reduces the likelihood of asthma by a factor of five

used for adjustment in all four surveys, was based on information from the first survey and may have changed over the observation period. It is, however, likely to be a conservative figure. A study from Newcastle, using a different method of calculation, reported adjusted rates of $33 \%$ and $22 \%$ above the crude response values for its first and second surveys, respectively. ${ }^{21}$

Only half of those replying to the first survey were included in these analyses, mainly because of the strict inclusion criteria and population mobility. Although this may have been a source of bias, no important differences were found between those responding on the first occasion only and those included in this study. Finally, for the analyses we combined four separate cohorts with different lengths of observation $(6,8,9$, and 11 years). To adjust for this, we included cohort as a potential predictor in the multivariate analyses.

\section{Conclusion}

Wheeze is transient in about three quarters of children aged less than 5 years presenting with the symptom. Using baseline exercise induced wheeze and a history of atopic disorders as predictors, it is possible to estimate a likelihood of future asthma in children presenting with preschool wheeze. The absence of baseline exercise induced wheeze and a history of atopic disorders reduces the likelihood of subsequent asthma by a factor of five. These findings are of importance for both clinicians and parents in planning future management.

We thank the patients and staff at the two general practices for their help and cooperation.

Contributors: PIF and TIF conceived and designed the study. JAM and PIF analysed the data. PIF and MLH drafted the article. All authors interpreted the results, critically revised the manuscript, and approved the final version for publication. PIF is guarantor of the paper.

Funding: The four surveys were funded by grants from the NHS Executive (RDO/28/1/01), Allen \& Hanburys, Manchester airport, and Astra Zeneca. None of the funding bodies had involvement in the data collection or analysis, the preparation of manuscripts or the decision to submit papers for publication.

Competing interests: PIF has received fees for attending meetings from GlaxoSmithKline and Merck Sharp \& Dohme and funds for research and travel grants from GlaxoSmithKline, Boehringer Ingelheim, and Merck Sharp \& Dohme. MLH has received a fee for speaking from Boehringer Ingelheim and travel grants from GlaxoSmithKline, Boehringer Ingelheim, and Merck Sharp \& Dohme. MFL has received travel grants from GlaxoSmithKline. TLF has received fees for speaking from

GlaxoSmithKline, Boehringer Ingelheim, Schering Plough, Pfizer, and Astra Zeneca; funds for research from GlaxoSmithKline, Boehringer Ingelheim, Merck Sharp \& Dohme, and Schering Plough; funds for consultancy from GlaxoSmithKline, Chiesi Pharmaceuticals, and Pharmacia; and travel grants from GlaxoSmithKline, Boehringer Ingelheim, Astra Zeneca, Chiesi Pharmaceuticals, and Merck Sharp \& Dohme.

Ethical approval: Ethical approval was not required for the first two postal questionnaire surveys. The last two surveys were approved by south Manchester local research ethics committee.

Provenance and peer review: Not commissioned; externally peer reviewed.

1 Lowe LA, Simpson A, Woodcock A, Morris J, Murray CS, Custovic A. Wheeze phenotypes and lung function in preschool children. $\mathrm{Am}$ J Respir Crit Care Med 2005;171:231-7.

2 Morgan WJ, Stern DA, Sherrill DL, Guerra S, Holberg CJ, Guilbert TW, et al. Outcome of asthma and wheezing in the first 6 years of life. Am J Respir Crit Care Med 2005;172:1253-8. 
3 Kurukulaaratchy RJ, Matthews S, Arshad SH. Does environment mediate earlier onset of the persistent childhood asthma phenotype? Pediatrics 2004;113:345-50.

4 Linehan MF, Hazell ML, Frank TL, Frank PI. Prevalence of respiratory symptoms in under 5s: 1993 to 2001. Arch Dis Child 2005;90:516-9.

5 Kuehni CE, Brooke AM, Silverman M. Prevalence of wheeze during childhood: retrospective and prospective assessment. Eur Resp J 2000;16:81-5.

6 Martinez FD. What have we learned from the Tucson children's respiratory study? Paediatr Respir Rev 2002;3:193-7.

7 Strunk RC. Defining asthma in the preschool-aged child. Pediatrics 2002;109(2 suppl):357-61.

8 Garcia-Marcos L, Suarez-Varela MM, Canflanca IM, Garrido JB, Quiros AB, Lopez-Silvarrey Varela A, et al. BCG immunization at birth and atopic diseases in a homogeneous population of Spanish schoolchildren. Int Arch Allergy Immunol 2005;137:303-9.

9 Masoli M, Fabian D, Holt S, Beasley R. The global burden of asthma: executive summary of the GINA Dissemination Committee report. Allergy 2004;59:469-78.

10 Taussig LM, Wright AL, Holberg CJ, Halonen M, Morgan WJ, Martinez FD. Tucson children's respiratory study: 1980 to present. J Allergy Clin Immunol 2003;111:661-75.

11 Turner SW, Palmer LJ, Rye PJ, Gibson NA, Judge PK, Cox M, et al. The relationship between infant airway function, childhood airway responsiveness and asthma. Am J Respir Crit Care Med 2004;169:921-7.

12 Frank P, Ferry S, Moorhead T, Hannaford P. Use of a postal questionnaire to estimate the likely under-diagnosis of asthma-like illness in adults. BrJ Gen Pract 1996;46:295-7.
13 Frank PI, Wicks PD, Hazell ML, Linehan MF, Hirsch S, Hannaford PC, et al. Temporal change in the prevalence of respiratory symptoms and obstructive airways disease 1993-2001. Br J Gen Pract 2005;55:596-602.

14 Butler D, Frost L, Morris J, Spence M, Stevens R, Young A. Health inequalities and Manchester in the 1990s. In: Stevens R, ed. Manchester: Manchester Health For All Working Party, 1993.

15 Keil U, Wieland S. International asthma and allergy study. Lancet 1992;340:46.

16 Kurukulaaratchy RJ, Fenn MH, Waterhouse LM, Matthews SM, Holgate ST, Arshad SH. Characterization of wheezing phenotypes in the first 10 years of life. Clin Exp Allergy 2003;33:573-8.

17 Kurukulaaratchy RJ, Matthews S, Holgate ST, Arshad SH. Predicting persistent disease among children who wheeze during early life. Eur Respir / 2003;22:767-71.

18 Osman M, Tagiyeva N, Wassall HJ, Ninan TK, Devenny AM, McNeill G, et al. Changing trends in sex specific prevalence rates for childhood asthma, eczema, and hay fever. Pediatr Pulmonol 2007;42:60-5.

19 Chinn S, Jarvis D, Burney P, Luczynska C, Ackerman-Liebrich U, Anto JM, et al. Increase in diagnosed asthma but not in symptoms in the European Community respiratory health survey. Thorax 2004;59:646-51.

20 Rhodes HL, Thomas P, Sporik R, Holgate ST, Cogswell JJ. A birth cohort study of subjects at risk of atopy. Am J Respir Crit Care Med 2002;165:176-80.

21 Barraclough R, Devereux G, Hendrick DJ, Stenton SC. Apparent but not real increase in asthma prevalence during the 1990s. Eur Resp J 2002;20:826-33.

Accepted: 9 April 2008 